\title{
Author Spotlight: C. Roberto Simons-Linares
}

\section{Roberto Simons-Linares ${ }^{1}$}

Published online: 30 April 2020

(c) Springer Science+Business Media, LLC, part of Springer Nature 2020

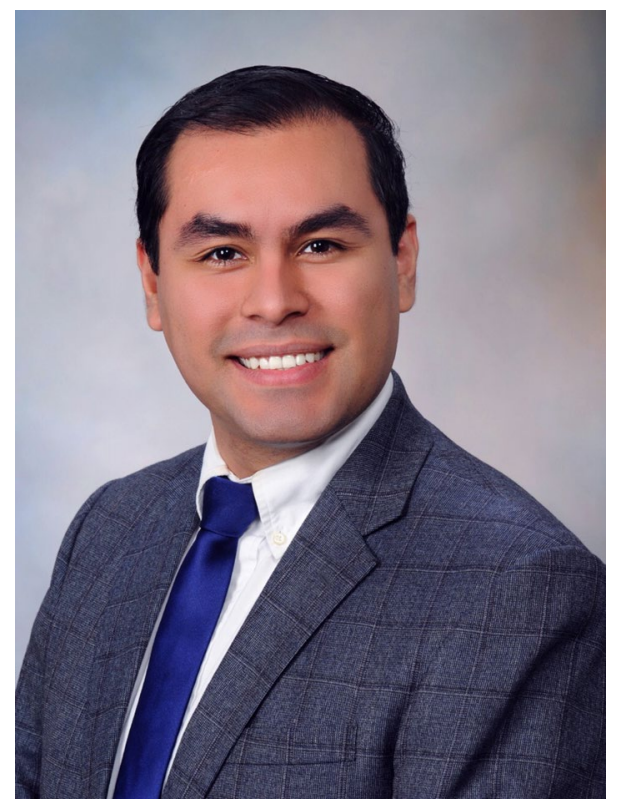

C. Roberto Simons-Linares, MD MSc., is currently a thirdyear gastroenterology fellow and the incoming interventional endoscopy fellow at the Cleveland Clinic. He serves as reviewer and associate editor for multiple journals, and he is currently the Editor-in-Chief for the American College of Gastroenterology (ACG) Case Reports journal. His research interests include pancreatobiliary diseases, interventional endoscopic ultrasound, bariatric endoscopy, artificial intelligence and innovation in endoscopy.

Publisher's Note Springer Nature remains neutral with regard to jurisdictional claims in published maps and institutional affiliations.

C. Roberto Simons-Linares

simonsc@ccf.org; robertosimons@outlook.com

1 Gastroenterology and Hepatology Department, Digestive Diseases and Surgery Institute, Cleveland Clinic, Cleveland, USA 